\title{
ON SOME TRACE INEQUALITIES
}

\section{Trung hoa Dinh, Raluca Dumitru, Jose A. Franco and Cong Trinh Le}

Abstract. In this paper we consider some generalizations of the Ando inequality

$$
|||f(A)-f(B)||| \leqslant|||f(|A-B|)|||
$$

with the "weight" $(A-B)^{p}$. More precisely, for $p \geqslant 1$ such that $(-1)^{p}=-1$ and for a nonnegative function $f$ on $[0, \infty)$ such that $f(0)=0$, we study the following inequality:

$$
\operatorname{Tr}\left((A-B)^{p}(f(A)-f(B))\right) \geqslant \operatorname{Tr}\left(|A-B|^{p} f(|A-B|)\right),
$$

whenever $A$ and $B$ are positive semidefinite matrices. We show that the inequality is true for any operator convex function $f$ and it is reversed whenever $f$ is operator monotone.

Mathematics subject classification (2010): 46L51, 47A30.

Keywords and phrases: Positive semidefinite matrices, trace inequalities, operator monotone functions, operator convex functions.

\section{REFERENCES}

[1] Ando, T., Comparison of norms $\||| f(A)-f(B) \mid\|$ and $\||| f(|A-B|) \mid\|$, Math. Z. 197(3), 403-410 (1988).

[2] Audenaert, K. M. R., Calsamiglia, J., Muñoz Tapia, R., Bagan, E., Masanes, Ll., ACin, A., Verstraete, F., Discriminating states: The quantum Chernoff bound, Phys. Rev. Lett. 98, 160501 (2007).

[3] Audenaert, K. M. R., Trace inequalities for completely monotone functions and Bernstein functions, Linear Algebra Appl. 437(2), 601-611 (2012).

[4] Bhatia, R., DAVIS, C., More matrix forms of the arithmetic-geometric mean inequality, SIAM J. Matrix Anal. Appl. 14(1), 132-136 (1993).

[5] Bourin, J. C., Matrix versions of some classical inequalities, Linear Algebra Appl. 416(2-3), 890907 (2006).

[6] Bourin, J. C., LEe, E. Y., Matrix inequalities from a two variables functional, Internat. J. Math. 27(09), 1650071 (2016).

[7] CARLen, E., Trace inequalities and quantum entropy: An introductory course, Contemporary mathematics 529, 73-140 (2010).

[8] Dinh, T. H., Ho, M. T., LE, C. T., Vo, B. K., Two trace inequalities for operator functions, to appear in Mathematical Inequalities and Applications (MIA), 2019.

[9] ZHAN, X., Matrix Inequalities, Lecture Notes in Mathematics, Springer-Berlin-Heidelberg, 2004.

[10] RiCARD, É., An inequality in noncommutative $L^{p}$-spaces, J. Math. Anal. Appl. 438(1), 53-58 (2016). 